\title{
Immuno-PET Quantitation of de2-7 Epidermal Growth Factor Receptor Expression in Glioma Using ${ }^{124}$ I-IMP-R4-Labeled Antibody ch806
}

Fook T. Lee ${ }^{1,2}$, Graeme J. O'Keefe ${ }^{3}$, Hui K. Gan ${ }^{1}$, Angela J. Mountain ${ }^{1}$, Gareth R. Jones ${ }^{3}$, Timothy H. Saunder ${ }^{3}$, Jessica Sagona ${ }^{3}$, Angela Rigopoulos ${ }^{1}$, Fiona E. Smyth ${ }^{1}$, Terrance G. Johns ${ }^{1,2}$, Serengulam V. Govindan ${ }^{4}$, David M. Goldenberg ${ }^{5}$, Lloyd J. Old ${ }^{1,6}$, and Andrew M. Scott ${ }^{1-3}$

${ }^{1}$ Ludwig Institute for Cancer Research, Heidelberg, Victoria, Australia; ${ }^{2}$ Department of Medicine, University of Melbourne, Austin Hospital, Victoria, Australia; ${ }^{3}$ Department of Nuclear Medicine and Centre for PET, Austin Hospital, Victoria, Australia; ${ }_{4}^{4}$ Immunomedics, Inc., Morris Plains, New Jersey; ${ }^{5}$ Garden State Cancer Center, Center of Molecular Medicine and Immunology, Belleville, New Jersey; and ${ }^{6}$ Memorial Sloan-Kettering Cancer Center, New York, New York

Overexpression, activation, and mutations of the epidermal growth factor receptor (EGFR) are commonly found in solid tumors. The aim of this study was to develop a PET-based method for detecting the constitutively active mutant de2-7 EGFR, which is associated with disease progression and resistance to chemotherapy and radiotherapy in glioma. Methods: The chimeric antibody ch806, which selectively binds an epitope of the EGFR that is exposed only on overexpressed, mutant, or ligand-activated forms of the receptor, was conjugated to the radiohalogen ${ }^{124} \mathrm{I}$ via the residualizing ligand IMP-R4, and in vitro properties were characterized. In vivo biodistribution and small-animal PET studies were performed in BALB/c nude mice bearing U87MG.de2-7 glioma xenografts. Imaging results were correlated with measured tumor uptake of the radioconjugate. Results: ${ }^{124}$ I-IMP-R4-ch806 had an immunoreactivity of $78.3 \%$ and was stable for $7 \mathrm{~d}$ when incubated in serum in vitro. The biodistribution analysis of ${ }^{124}$ I-IMP-R4-ch806 demonstrated a maximal uptake of $30.95 \pm 6.01$ percentage injected dose per gram (\%ID/g) in U87MG.de2-7 xenografts at $48 \mathrm{~h}$ after injection, with prolonged tumor retention $(6.07 \pm 0.80 \% \mathrm{ID} / \mathrm{g}$ at $216 \mathrm{~h}$ after injection). The tumor-to-blood ratio increased from 0.44 at $4 \mathrm{~h}$ after injection to a maximum of 4.70 at $168 \mathrm{~h}$ after injection. PET of 124I-IMP-R4-ch806 biodistribution was able to clearly detect the U87MG.de2-7 tumors at $24 \mathrm{~h}$ after injection and for at least $168 \mathrm{~h}$ after injection. Correlation between tumor PET image quantitation of ${ }^{124} \mathrm{I}-\mathrm{IMP}-\mathrm{R} 4-\mathrm{ch} 806$ and $\% \mathrm{ID} / \mathrm{g}$ determined from resected tissues $(r=0.9350)$ was excellent. Conclusion: These results show that immuno-PET with ${ }^{124}$ I-IMP-R4-ch806 is feasible and allows noninvasive quantitation of de2-7 EGFR expression in vivo.

Received Jul. 13, 2009; revision accepted Feb. 22, 2010.

For correspondence or reprints contact: Andrew M. Scott, Ludwig Institute for Cancer Research, Austin Hospital, Studley Rd., Heidelberg, Victoria 3084, Australia.

E-mail: andrew.scott@ludwig.edu.au

COPYRIGHT @ 2010 by the Society of Nuclear Medicine, Inc.
Key Words: monoclonal antibody; glioma; mutant epidermal growth factor receptor; PET

J Nucl Med 2010; 51:967-972

DOI: 10.2967/jnumed.109.068395

$\mathbf{M}$ onoclonal antibodies (mAbs) are an established therapeutic tool in oncology for immunotherapy and signaling abrogation of tumor cells and as carrier molecules to deliver a toxic load (e.g., radioimmunotherapy) (1). More recently, these antibodies have been labeled with positron emitters for use as a diagnostic tool in combination with PET scanning (immuno-PET) (1-4). This technique has been developed to allow the noninvasive, high-resolution, quantitative imaging of tumors using $\mathrm{mAbs}$ raised against tumorspecific or -prevalent antigens. Potential applications of immuno-PET include aiding in antibody development and in patient selection for antibody therapy either by confirming the presence of antibody binding in patients planned for immunotherapy or by determining the radiation dosimetry in patients planned for radioimmunotherapy $(1,2)$.

The epidermal growth factor receptor (EGFR) is an attractive target for tumor-targeted antibody therapy because it is overexpressed in many types of epithelial tumors and is associated with poor prognosis in several tumor types (5). Overexpression of the receptor is often caused by amplification of the EGFR gene, an event also linked with EGFR mutation (6). The de2-7 EGFR (or EGFRvIII) extracellular truncation of the EGFR is the most common EGFR mutation and is frequently expressed in glioblastoma and some other tumor types, including prostate and breast cancer (7). Inhibition of the EGFR by mAbs and tyrosine kinase is a rational strategy for the development of new cancer 
therapeutics, because of the high expression on epithelial tumors and the role of EGFR signaling in maintaining the neoplastic phenotype of cancer cells. Consequently, several anti-EGFR therapeutics have been reported in the literature, with several undergoing clinical evaluation (5).

We have previously described ch806, a chimeric form of a novel anti-EGFR antibody that binds the EGFR deletion variant de2-7 EGFR and wild-type EGFR expressed in cells overexpressing the receptor. ch806 has negligible binding to normal tissues-including the skin and liver-that express physiologic levels of EGFR (8-15). We have shown in a Phase I trial that ch806 has impressive therapeutic activity in preclinical models and specifically targets tumors but not normal tissues $(10,16)$. In previous studies, we have shown that ch806 directly labeled with ${ }^{125}$ I shows minimal tumor retention, most likely a result of this internalized antibody being catabolized (10). To develop a noninvasive method for targeting and quantitating de2-7 EGFR expression in glioma, we have developed an immuno-PET technique using ch806 conjugated with ${ }^{124} \mathrm{I}$ via the residualizing ligand IMP-R4 (IMP-R4 is MCCLys(MCC)-Lys(X)-D-Tyr-D-Lys(X)-OH, wherein MCC is 4 -(N-maleimidomethyl)-cyclohexane-1-carbonyl and $\mathrm{X}$ is 1-((4-thiocarbonylamino)benzyl)-diethylenetriaminepentaacetic acid) (17), resulting in specific tumor localization and high-resolution PET images of glioma xenografts.

\section{MATERIALS AND METHODS}

All analytic-grade reagents, except where stated, were obtained from Merck Pty. Ltd. ${ }^{124} \mathrm{I}$ in $0.02 \mathrm{~N} \mathrm{NaOH}(370 \mathrm{MBq} / \mathrm{mL}$ $[10 \mathrm{mCi} / \mathrm{mL}])$ was purchased from Advanced Nuclide Technologies. The residualizing peptide IMP-R4 was provided by Immunomedics, Inc. Radioactivity was measured either with a dose calibrator (Atomlab-100; Biodex) or an automated $\gamma$-counter (Cobra II; Canberra-Packard).

\section{Antibodies and Cells}

The ch806 and huA33 mAbs (IgG1) were produced (Biologic Production Facility, LICR) as previously described $(3,10,18)$. The A33-expressing colorectal cancer cell line SW1222 and the transfected human glioblastoma cell line U87MG.de2-7 that expresses the de2-7 EGFR have been described previously $(3,11)$.

\section{Radiolabeling}

Detailed radiolabeling conditions using IMP-R4 have been reported previously (17). In brief, $0.53 \mathrm{mg}$ of ch806 antibody $(5.3 \mathrm{mg} / \mathrm{mL})$ was reduced with a 60 -fold excess of dithiothreitol for $40 \mathrm{~min}$ at room temperature. The treated antibody was then purified twice using a centrifugal chromatographic technique (19) with two 3.0-mL columns of Sephadex G50 equilibrated with deaerated 0.1 M sodium phosphate buffer, $\mathrm{pH}$ 6.6, containing $5 \mathrm{mM}$ ethylenediaminetetraacetic acid. Before antibody purification, the IMP-R4 peptide was radiolabeled by neutralizing the $\mathrm{pH}$ of $0.1 \mathrm{~mL}$ of ${ }^{124} \mathrm{I}-\mathrm{NaOH}$ using $0.1 \mathrm{~mL}$ of $0.5 \mathrm{M}$ potassium phosphate buffer, $\mathrm{pH}$ 7.0. An aliquot of IMP-R4 $(31 \mu \mathrm{g})$ was added to the mixture, followed by IODO-GEN (Pierce) precoated glass beads (a $0.5 \mathrm{mg} / \mathrm{mL}$ concentration of IODO-GEN in chloroform). After $20 \mathrm{~min}$, the mixture was transferred to an Eppendorf tube containing $9.0 \mu \mathrm{L}$ of $20 \mathrm{mM}$ 4-hydroxyphenylacetic acid dissolved in $40 \mathrm{mM}$ sodium phosphate buffer, $\mathrm{pH}$ 7.4. The reduced antibody was then added to the radioactive mixture and incubated for a further $30 \mathrm{~min}$ at room temperature. The radiolabeled antibody was subsequently purified under gravity using a 5-mL Sephadex G50 column equilibrated in saline.

\section{Immunoreactivity Assays}

The immunoreactivity of antibody ${ }^{124}$ I-IMP-R4-ch806 was determined using the Lindmo assay. This cell-based assay comprised incubation of $20 \mathrm{ng}$ of radiolabeled antibody with increasing concentrations of antigen-expressing U87MG.de2-7 cells (ranging from $0 \times 10^{6}$ cells to $5.0 \times 10^{6}$ cells in $1.0 \mathrm{~mL}$ of cell culture medium) and continuous mixing on a rotation device. After $45 \mathrm{~min}$ at room temperature, the cells were centrifuged and washed 3 times with medium before radioactive counting to determine the extent of binding in comparison to known standards. To demonstrate the specificity of binding, $20 \mu \mathrm{g}$ of unlabeled ch806 were added to the assays and extent of binding determined similarly. Scatchard assays were also performed. Serial dilutions starting from $10 \mu \mathrm{g} / \mathrm{mL}$ of unlabeled ch806 antibody were added to $20 \mathrm{ng}$ of labeled antibody, followed by the addition of $1.0 \times 10^{6}$ U87MG.de2-7 cells.

The stability of ${ }^{124}$ I-IMP-R4-ch806 was determined by incubating $10 \mu \mathrm{g}$ in $80 \mu \mathrm{L}$ of human serum (final volume, $106 \mu \mathrm{L}$ ) for periods up to $7 \mathrm{~d}$ at $37^{\circ} \mathrm{C}$. An aliquot of the mixture was diluted for analysis of radiochemical purity on instant thin-layer chromatography silica gel-impregnated glass fibers developed with $10 \%$ trichloroacetic acid and immunoreactivity assays (single point with $5 \times 10^{6}$ U87MG.de2-7 cells $/ \mathrm{mL}$ ) on days 3 and 7 . The immunoreactivities of ${ }^{124}$ I-IMP-R4-huA33 $\left(5.0 \times 10^{6}\right.$ LIM 1215 cells $/ \mathrm{mL})$ and directly labeled ${ }^{124} \mathrm{I}$-ch806 $\left(5 \times 10^{6}\right.$ U87MG.de2-7 cells $/ \mathrm{mL}$ ) were determined similarly.

\section{Animals and Tumors}

The U87MG.de2-7 cell line and the A33 antigen-expressing control cell line SW1222 were grown in RPMI 1640 with standard additives and 5\% fetal calf serum. Cells were harvested at the point of confluence using phosphate-buffered saline $/ 0.05 \%$ ethylenediaminetetraacetic acid (w/v) and resuspended in medium. Approximately $3.0 \times 10^{6}$ U87MG.de2-7 cells in $0.1 \mathrm{~mL}$ of phosphate-buffered saline were injected subcutaneously into the flanks of 3- to 4-wk-old female BALB/c nude mice. Tumors were measured using the formula $\left(\mathrm{L} \times \mathrm{W}^{2}\right) \times 0.5$, where length $(\mathrm{L})$ was the maximal measurement of the tumor and width (W) was the measurement perpendicular to it (3).

\section{Biodistribution Studies and Measurement of Tumor Weight}

Two weeks after tumor inoculation, mice received tail vein injections of a sterile filtered mixture of $8.6 \mu \mathrm{g}$ of ${ }^{124} \mathrm{I}$-IMP-R4ch806 $(159.1 \mathrm{kBq}[4.3 \mu \mathrm{Ci}])$ in $0.1 \mathrm{~mL}$ of $0.01 \% \mathrm{w} / \mathrm{v}$ human serum albumin in saline. Biodistribution was studied and tumors were weighed at $4,24,48,72,120,168$, and $216 \mathrm{~h}$ after injection of ${ }^{124}$ I-IMP-R4-ch806. At each time point, 5 mice were sacrificed by isoflurane (Forane; Baxter) overinhalation, followed by cervical dislocation. The total blood volume was collected by exsanguination via cardiac puncture. Tumors and organs (skin, liver, spleen, intestine, stomach, kidneys, brain, femoral bone, lungs, and heart) were then harvested, blotted dry, and weighed (Sartorius Basic Balance). All samples were counted in a $\gamma$-scintillation counter (Cobra II; Canberra-Packard) set for the 540-keV window. Calibrated standards of a known radioactive 
concentration prepared from the injected material were subsequently scanned with each mouse measurement, thereby enabling tumor uptake to be corrected for the physical decay of the isotope.

Two controls were included in this study. An $\mathrm{IgG}_{1}$ isotype control antibody, humanized huA33, was similarly radiolabeled with ${ }^{124} \mathrm{I}$ via the residualizing ligand IMP-R4. The resultant ${ }^{124} \mathrm{I}$ IMP-R4-huA33 $(40.7 \mathrm{kBq}[1.1 \mu \mathrm{Ci}] / 5.5 \mu \mathrm{g})$ was also injected into U87MG.de2-7 tumor-bearing mice, and its biodistribution was assessed at $4 \mathrm{~h}$ and at day 3 after injection. The second control consisted of injecting mice with directly labeled ${ }^{124} \mathrm{I}$-ch806 (125.8 $\mathrm{kBq}[3.4 \mu \mathrm{Ci}] / 5.2 \mu \mathrm{g})$ and assessing its biodistribution at day 3 after injection.

Results of labeled antibody distribution over time were expressed as percentage injected dose per gram $(\% \mathrm{ID} / \mathrm{g}$ ) ([counts per minute for tissue sample/counts per minute for standard] $\times 100 /$ weight in grams) and as tumor-to-blood ratios. Blood clearance kinetics were determined using a curve-fitting program (WinNonlin, version 5.2; Pharsight), assuming a 2-compartment model. Cumulative retention of radiolabeled ch806 by tumor was determined by integrating the area under the time-activity curve for localization in xenografts, and the results were expressed as \%ID/ $\mathrm{g} / \mathrm{h}$.

\section{PET/CT Camera Imaging}

PET/CT was performed at $4,24,48$, and $168 \mathrm{~h}$ after injection. Two mice were examined by PET/CT at each of these time points. Mice were anesthetized with a mixture of ketamine and xylaxine. If necessary, parenteral anesthesia was supplemented with inhalational anesthesia during scanning using a nose cone containing cotton wool saturated with isoflurane under an approved animal ethics protocol (Austin Health Animal Ethics Committee). PET/CT images were acquired on a Philips Gemini- 2 camera. The CT tube voltage was reduced to the minimum of $90 \mathrm{kV}$ to improve contrast and to allow a higher anode current for better signalto-noise ratio. Mice were scanned simultaneously, with scan durations varying from $900 \mathrm{~s}$ on day 0 to $2,700 \mathrm{~s}$ on day 7 . The PET emission scans were corrected for attenuation using the ${ }^{137} \mathrm{Cs}$ singles-acquired transmission scans. The scans were then reconstructed using the row-action maximization-likelihood algorithm with 3-dimensional reconstruction, with standardized uptake values (SUVs) based on the mean mouse weight and the injected activity. In addition, an imaging standard comprising $10 \%$ of the injected dose was placed within the field of view for reference.

\section{PET/CT and Biodistribution Comparison}

The results of tumor volume and CT-derived tumor volume were determined and compared by linear regression analysis. The mouse PET scans were reconstructed to give SUV images, and the mouse CT images were used to define the xenograft region of interest (ROI). This ROI was then used with the coregistered PET images to determine the tumor volume and uptake of ${ }^{124}$ I-IMPR4-ch806 in units of SUV. The resultant maximum SUV for the ROI was corrected for the effects of partial volume from a recovery coefficient calibration and then compared with the resected xenograft-determined $\% \mathrm{ID} / \mathrm{g}$.

As a result of the finite spatial resolution of the reconstructed PET images, the SUV required correction for recovery loss. The recovery coefficient was quantified by measuring the SUV for a series of spheres with volumes ranging from 0.59 to $20.19 \mathrm{~mL}$. These spheres were filled with a $100 \mathrm{kBq} / \mathrm{mL}$ concentration of ${ }^{124}$ I-IMP-R4-ch806 and then scanned and reconstructed. The PET/
CT-derived tumor concentration of ${ }^{124}$ I-IMP-R4-ch806 was compared with biodistribution data by linear regression analysis.

\section{RESULTS}

In Vitro Properties of ${ }^{124}$ I-Radioconjugated Antibodies

Ch806 was radiolabeled to a specific activity of 19.61 $\mathrm{MBq} / \mathrm{mg}(0.53 \mathrm{mCi} / \mathrm{mg})$ of protein, with a labeling efficiency of $51.2 \%$. Analysis of radioactivity showed that $96.6 \%$ of ${ }^{124} \mathrm{I}$ was bound to protein, as determined by thinlayer chromatography. Radiolabeled antibody retained immunoreactivity to de2-7 EGFR-expressing cells with $78.3 \%$ binding using the Lindmo assay. The apparent association constant determined by Scatchard analysis was $5.6 \times 10^{8}$ $\mathrm{M}^{-1}$, and the number of antibodies bound per cell was $1.12 \times$ $10^{6}$ (data not shown). The stability of the radioconjugate was demonstrated by immunoreactivities of $52.1 \%$ and $34.3 \%$ on days 3 and 7, respectively, and high-performance liquid chromatography analysis of samples confirmed the integrity of labeled antibody over time.

For controls, the ${ }^{124}$ I-IMP-R4-huA33 was prepared at a specific radioactivity of $7.4 \mathrm{MBq} / \mathrm{mg}(0.2 \mathrm{mCi} / \mathrm{mg})$, with $95.4 \%$ of ${ }^{124} \mathrm{I}$ being bound to protein, and with an immunoreactivity of $55.6 \%$. The directly labeled ${ }^{124} \mathrm{I}$-ch806 was prepared at $22.2 \mathrm{MBq} / \mathrm{mg}(0.6 \mathrm{mCi} / \mathrm{mg}), 97.1 \%$ of ${ }^{124} \mathrm{I}$ was bound to protein, and the immunoreactivity was $77.2 \%$.

\section{Biodistribution}

The biodistribution properties of ${ }^{124}$ I-IMP-R4-ch806 in xenografted mice are shown in Figure 1A. The mean uptake of ${ }^{124}$ I-IMP-R4-ch806 by U87MG.de2-7 xenografts reached a maximum of $30.95 \pm 6.01 \% \mathrm{ID} / \mathrm{g}$ at $48 \mathrm{~h}$ after injection, when the mean tumor weight was $0.29 \pm 0.13 \mathrm{~g}$ (range, $0.13-0.45 \mathrm{~g}$ ). Tumor uptake was $14.64 \pm 2.52 \%$ ID/ $\mathrm{g}$ by $120 \mathrm{~h}$ after injection. This apparent decrease may be due in part to the rapid growth of these aggressive tumor xenografts between the 2 time points; they had almost tripled in weight between the 48- and 120-h measurements (mean weight, $0.83 \pm 0.29 \mathrm{~g}$ at $120 \mathrm{~h}$; range, 0.49-1.16 g). The tumor-to-blood ratios increased from $0.45 \pm 0.07$ (at $4 \mathrm{~h}$ after injection) to $5.25 \pm 2.45$ (120 h after injection). Uptake in normal tissues (e.g., skin and liver) was low, with a time-dependent decrease paralleling that in the blood. The blood $\alpha$-half-life $\left(\mathrm{t}_{1 / 2}\right)$ was $3.47 \pm 0.34 \mathrm{~h}, \beta-\mathrm{t}_{1 / 2}$ was $56.63 \pm 14.53 \mathrm{~h}$, and area under the curve was $159.18 \mathrm{~h} / \mathrm{ng} /$ $\mathrm{mL}$, with a clearance value of $62.82 \pm 14.5 \mathrm{~mL} / \mathrm{h}$.

The specificity of tumor targeting was demonstrated using an isotype control $\operatorname{IgG}_{1}$-humanized mAb huA33. The biodistribution of ${ }^{124}$ I-IMP-R4-huA33 at 4 and $72 \mathrm{~h}$ is shown in Figure 1B. At $4 \mathrm{~h}$ after injection, the amount of radioconjugate in U87MG.de2-7 tumors was $6.96 \pm 0.67$ $\%$ ID/g. By $72 \mathrm{~h}$ after injection, the corresponding value was $7.85 \pm 0.56 \% \mathrm{ID} / \mathrm{g}$ tumor. The tumor-to-blood ratio was low $(0.68 \pm 0.08)$, indicating a lack of specific uptake. A second biodistribution study with directly labeled ${ }^{124} \mathrm{I}-$ ch806 at $72 \mathrm{~h}$ after injection (Fig. 1C) also showed low 

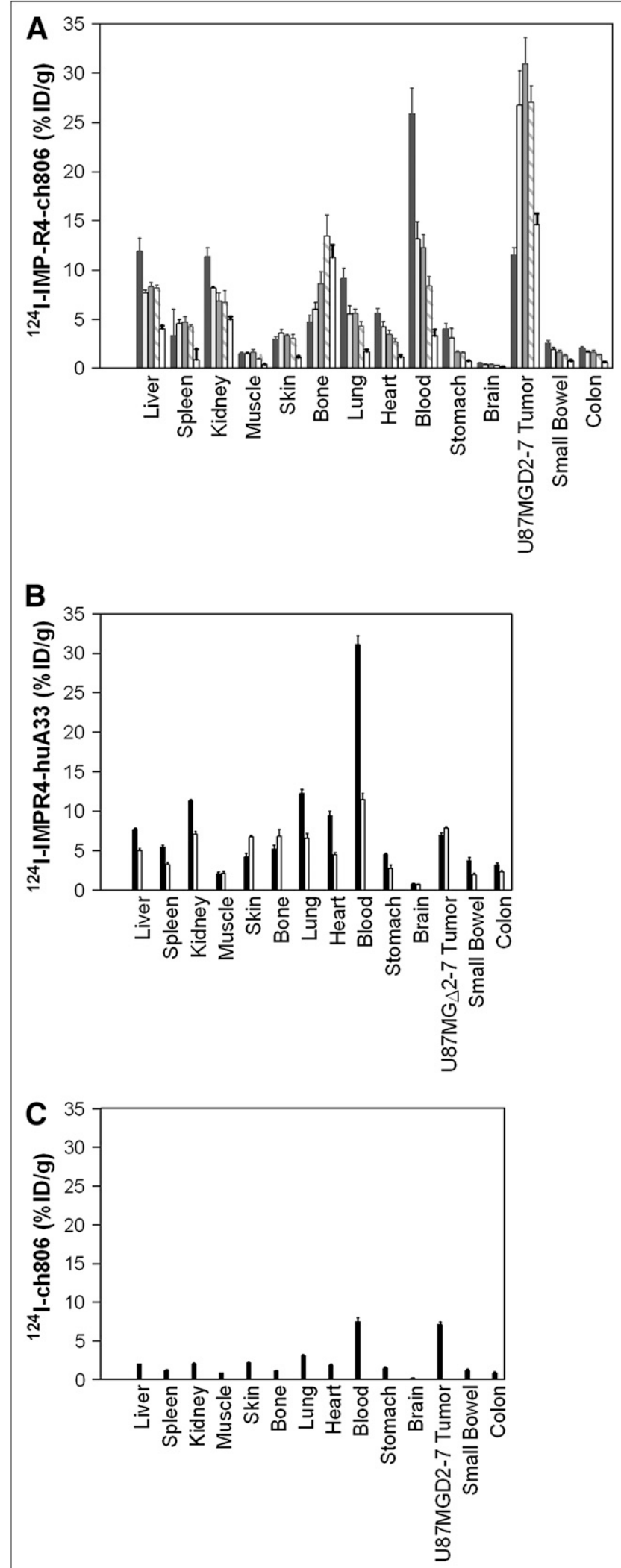

FIGURE 1. Biodistribution properties of ${ }^{124}$ I-IMP-R4-ch806 and control constructs in BALB/C nude mice bearing U87MG.de2-7 xenografts. Results of biodistribution of ${ }^{24}$ IMP-R4-ch806 (left to right) at 4, 24, 48, 72, and $120 \mathrm{~h} \mathrm{(A),}$ de2-7 EGFR tumor uptake at $72 \mathrm{~h}(7.14 \pm 0.62 \% \mathrm{ID} / \mathrm{g})$, with a tumor-to-blood ratio of $0.96 \pm 0.08$.

\section{PET/CT}

Tumor uptake of ${ }^{124}$ I-IMP-R4-ch806 was evident by $24 \mathrm{~h}$ after injection and increased with time. No normal tissue uptake was evident, consistent with the biodistribution studies. Uptake of ${ }^{124}$ I-IMP-R4-ch806 in de2-7 EGFRexpressing tumor increased over time, and prolonged retention was evident even up to $168 \mathrm{~h}$ after injection (Fig. 2).

\section{Correlative Analyses}

Comparison of the directly measured xenograft mass $\left(\mathrm{M}_{\text {xenograft }}\right)$ and $\mathrm{CT}$-determined volume $\left(\mathrm{CT}_{\mathrm{vol}}\right)$ showed a strong linear correlation between the mass and volume parameters $\left(\mathrm{M}_{\text {xenograft }}=1.40 \times \mathrm{CT}_{\mathrm{vol}}, r=0.9708\right)$. The corrected maximum SUV for the mouse tumor ROI was compared with the \%ID/g determined in resected xenografts, the results of which are displayed in Figure 3. An excellent correlation $(r=0.9350)$ was obtained after recovery coefficient correction.

\section{DISCUSSION}

We report on the successful use of immuno-PET with ch806 labeled with ${ }^{124}$ I via the residualizing ligand IMP-R4 to detect xenografts expressing de2-7 EGFR. We selected ${ }^{124} \mathrm{I}$ as our radiolabel because it is readily available and has a sufficiently long $\mathrm{t}_{1 / 2}(4.2 \mathrm{~d})$ to make it compatible with the biodistribution properties of intact antibodies such as ch806. The quantitation of ${ }^{124} \mathrm{I}$-ch806 uptake was significantly correlated with well counter-based quantitation, despite the small volume of tumors. Although several studies have been published regarding immuno-PET using short-lived $\left(\mathrm{t}_{1 / 2}, 1-2 \mathrm{~h}\right)$ positron emitters such as ${ }^{18} \mathrm{~F}$-FDG (20) or ${ }^{68} \mathrm{Ga}(21-23)$, these are suitable only for antibody fragments or smaller antibody constructs because of their short $\mathrm{t}_{1 / 2}$. Although the medium-lived $\left(\mathrm{t}_{1 / 2}, 12-16 \mathrm{~h}\right)$ isotopes such as ${ }^{64} \mathrm{Cu}(24-27),{ }^{86} \mathrm{Y}(28,29)$, and ${ }^{76} \mathrm{Br}(30,31)$ have been used to label both intact antibodies and partial antibody constructs, the most favorable isotopes for labeling whole antibodies are long-lived isotopes such as ${ }^{124} \mathrm{I}$ or ${ }^{89} \mathrm{Zr}(3,4,32)$. Both ${ }^{124} \mathrm{I}(33,34)$ and ${ }^{89} \mathrm{Zr}(32,35-38)$ have been conjugated to $m A b s$ in preclinical $(1,3,32,35-37)$ and clinical studies $(33,34,37,38)$.

It was necessary to conjugate ${ }^{124} \mathrm{I}$ to ch806 using the residualizing peptide IMP-R4 to increase tumor retention of the labeled antibody, because ch806 is internalized by de27 EGFR-expressing cells, which leads to dehalogenation of radioiodine to antibody with standard tyrosine linkage (15). The residualizing peptide IMP-R4 provides a conjugation method that can be successfully applied to animal studies

124|-IMP-R4-huA33 (4 and 72 h) (B), and ${ }^{124 \mid-c h 806 ~ d i r e c t ~}$ conjugate $(72 \mathrm{~h})(\mathrm{C})$ in $\mathrm{BALB} / \mathrm{c}$ nude mice bearing U87MG.de2-7 xenografts. Results are shown for each tissue as mean $( \pm \mathrm{SD}) \% \mathrm{ID} / \mathrm{g}$ values. 


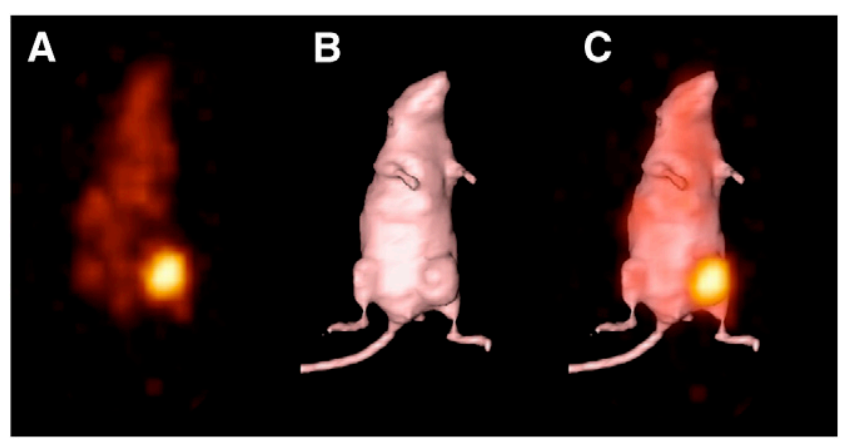

FIGURE 2. Immuno-PET of de2-7 EGFR expression in glioma xenografts. Small-animal PET image at $168 \mathrm{~h}$ after injection (A), 3-dimensional surface-rendered CT image (B), and fused immuno-PET and CT image (C).

and potentially to human trials. Conjugation with IMP-R4 did not alter the functional characteristic of ch806 in vitro, with the affinity, number of receptors bound, and immunoreactivity of ${ }^{124}$ I-IMP-R4-ch806 being highly comparable to the murine antibody (13) and similar to the same antibody labeled with ${ }^{111}$ In $(10,39)$. Although the immunoreactivity of ${ }^{124} \mathrm{I}-\mathrm{IMP}-\mathrm{R} 4-\mathrm{ch} 806$ did decline with time, the results are consistent with other immunoconjugates successfully applied in the clinic $(16,18)$.

${ }^{124}$ I-IMP-R4-ch806 also retained specificity for tumorexpressed de2-7 EGFR, with no significant binding to normal tissues observed. This specificity is consistent with that observed for ch806 for tumor-expressed EGFR seen in patients (16) and in marked contrast to the high liver uptake seen with ${ }^{111}$ In-C225 anti-EGFR antibody in clinical trials (40). ${ }^{124}$ I-IMP-R4-ch806 was also an excellent molecular imaging agent for PET/CT. The ability to capture highresolution images was evident from $24 \mathrm{~h}$ after injection and persisted until $168 \mathrm{~h}$ after injection, when the xenografts remained clearly visible on PET. There was also an

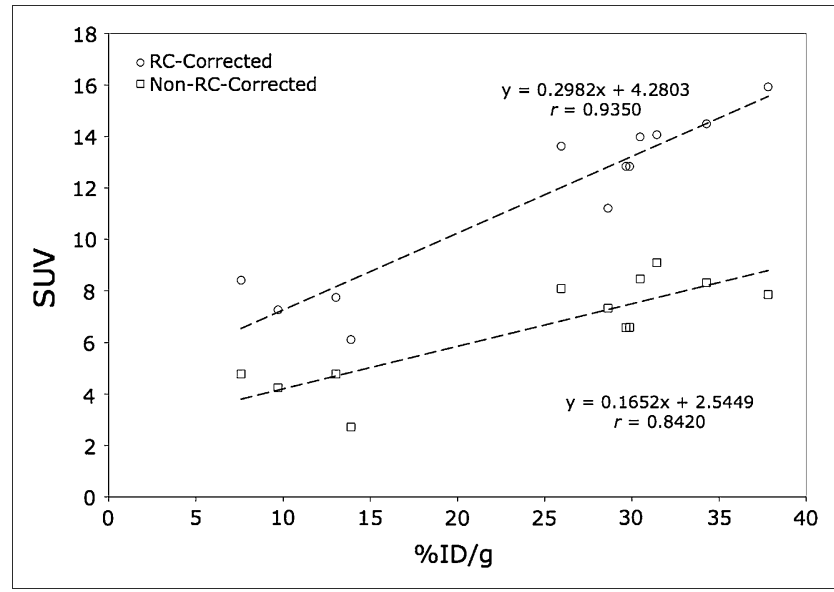

FIGURE 3. Recovery coefficient (RC)-corrected and noncorrected maximum SUV vs. measured ${ }^{124} \mathrm{I}$-ch $806 \% \mathrm{ID} / \mathrm{g}$ illustrating time distribution of xenograft samples. excellent correlation between the assessment of tumor volume determined by $\mathrm{CT}$ and the tumor weight determined at necropsy. The volumes of the lesions determined from CT were used subsequently to correct the tumor uptake for partial-volume effect. Immuno-PET was able to detect tumors as small as $230 \mathrm{~mm}^{3}$ in this experiment, showing the high resolution and specificity of this method. More important, there was good correlation between the quantification of ${ }^{124}$ I-IMP-R4-ch806 uptake by PET and by direct measurement at necropsy $\left(r^{2}=0.8743\right)$.

\section{CONCLUSION}

We have shown that the radiohalogen ${ }^{124}$ I can be used for indirect labeling of ch806, allowing high-resolution imaging and quantification of de2-7 EGFR expression in gliomas. We also confirm the high tumor specificity of ch806, indicating that it has therapeutic potential both as a naked antibody and as a carrier antibody for payloads (e.g., radioisotopes, toxins). Because the conditions that allow ch806 binding (EGFR overexpression, mutation, and ligand activation) are essentially restricted to tumors $(8,39)$, immuno-PET with ch806 may have an important role in the noninvasive molecular characterization of EGFR-expressing tumors in patients.

\section{ACKNOWLEDGMENTS}

This work was supported in part by NHMRC Program grants 280916 and 487922 .

\section{REFERENCES}

1. Nagengast WB, de Vries EG, Hospers GA, et al. In vivo VEGF imaging with radiolabeled bevacizumab in a human ovarian tumor xenograft. $\mathrm{J} \mathrm{Nucl} \mathrm{Med}$. 2007;48:1313-1319.

2. Verel I, Visser GW, van Dongen GA. The promise of immuno-PET in radioimmunotherapy. $J$ Nucl Med. 2005;46(suppl 1):164S-171S.

3. Lee FT, Hall C, Rigopoulos A, et al. Immuno-PET of human colon xenograftbearing BALB/c nude mice using ${ }^{124} \mathrm{I}-\mathrm{CDR}$-grafted humanized A33 monoclonal antibody. J Nucl Med. 2001;42:764-769.

4. Lee FT, Scott AM. Immuno-PET for tumor targeting. J Nucl Med. 2003;44: 1282-1283.

5. Baselga J, Arteaga CL. Critical update and emerging trends in epidermal growth factor receptor targeting in cancer. J Clin Oncol. 2005;23:2445-2459.

6. Sugawa N, Ekstrand AJ, James CD, Collins VP. Identical splicing of aberrant epidermal growth factor receptor transcripts from amplified rearranged genes in human glioblastomas. Proc Natl Acad Sci USA. 1990;87:8602-8606.

7. Wikstrand CJ, Reist CJ, Archer GE, Zalutsky MR, Bigner DD. The class III variant of the epidermal growth factor receptor (EGFRvIII): characterization and utilization as an immunotherapeutic target. J Neurovirol. 1998;4:148-158.

8. Johns TG, Adams TE, Cochran JR, et al. Identification of the epitope for the epidermal growth factor receptor-specific monoclonal antibody 806 reveals that it preferentially recognizes an untethered form of the receptor. $J$ Biol Chem. 2004;279:30375-30384.

9. Jungbluth AA, Stockert E, Huang HJ, et al. A monoclonal antibody recognizing human cancers with amplification/overexpression of the human epidermal growth factor receptor. Proc Natl Acad Sci USA. 2003;100:639-644.

10. Panousis C, Rayzman VM, Johns TG, et al. Engineering and characterisation of chimeric monoclonal antibody 806 (ch806) for targeted immunotherapy of tumours expressing de2-7 EGFR or amplified EGFR. Br J Cancer. 2005;92: 1069-1077.

11. Luwor RB, Johns TG, Murone C, et al. Monoclonal antibody 806 inhibits the growth of tumor xenografts expressing either the de2-7 or amplified epidermal 
growth factor receptor (EGFR) but not wild-type EGFR. Cancer Res. 2001;61: 5355-5361.

12. Mishima K, Johns TG, Luwor RB, et al. Growth suppression of intracranial xenografted glioblastomas overexpressing mutant epidermal growth factor receptors by systemic administration of monoclonal antibody (mAb) 806, a novel monoclonal antibody directed to the receptor. Cancer Res. 2001;61:5349-5354.

13. Johns TG, Stockert E, Ritter G, et al. Novel monoclonal antibody specific for the de2-7 epidermal growth factor receptor (EGFR) that also recognizes the EGFR expressed in cells containing amplification of the EGFR gene. Int $J$ Cancer. 2002;98:398-408.

14. Perera RM, Narita Y, Furnari FB, et al. Treatment of human tumor xenografts with monoclonal antibody 806 in combination with a prototypical epidermal growth factor receptor-specific antibody generates enhanced antitumor activity. Clin Cancer Res. 2005;11:6390-6399.

15. Perera RM, Zoncu R, Johns TG, et al. Internalization, intracellular trafficking, and biodistribution of monoclonal antibody 806: a novel anti-epidermal growth factor receptor antibody. Neoplasia. 2007;9:1099-1110.

16. Scott AM, Lee F-T, Tebbutt N, et al. A phase I clinical trial with monoclonal antibody ch806 targeting transitional state and mutant epidermal growth factor receptors. Proc Natl Acad Sci USA. 2007;104:4071-4076.

17. Govindan SV, Griffiths GL, Stein R, et al. Clinical-scale radiolabeling of a humanized anticarcinoembryonic antigen monoclonal antibody, hMN-14, with residualizing ${ }^{131} \mathrm{I}$ for use in radioimmunotherapy. $J$ Nucl Med. 2005;46:153-159.

18. Scott AM, Lee FT, Jones R, et al. A phase I trial of humanized monoclonal antibody A33 in patients with colorectal carcinoma: biodistribution, pharmacokinetics, and quantitative tumor uptake. Clin Cancer Res. 2005;11:4810-4817.

19. Penefsky HS. A centrifuged-column procedure for the measurement of ligand binding by beef heart F1. Methods Enzymol. 1979;56:527-530.

20. Vaidyanathan G, Bigner DD, Zalutsky MR. Fluorine-18-labeled monoclonal antibody fragments: a potential approach for combining radioimmunoscintigraphy and positron emission tomography. J Nucl Med. 1992;33:1535-1541.

21. Schuhmacher J, Kaul S, Klivenyi G, et al. Immunoscintigraphy with positron emission tomography: gallium- 68 chelate imaging of breast cancer pretargeted with bispecific anti-MUC1/anti-Ga chelate antibodies. Cancer Res. 2001;61:3712-3717.

22. Griffiths GL, Chang C-H, McBride WJ, et al. Reagents and methods for PET using bispecific antibody pretargeting and ${ }^{68} \mathrm{Ga}$-radiolabeled bivalent haptenpeptide-chelate conjugates. J Nucl Med. 2004;45:30-39.

23. Smith-Jones PM, Solit DB, Akhurst T, Afroze F, Rosen N, Larson SM. Imaging the pharmacodynamics of HER2 degradation in response to Hsp90 inhibitors. Nat Biotechnol. 2004;22:701-706.

24. Cai W, Chen K, He L, Cao Q, Koong A, Chen X. Quantitative PET of EGFR expression in xenograft-bearing mice using ${ }^{64} \mathrm{Cu}$-labeled cetuximab, a chimeric anti-EGFR monoclonal antibody. Eur J Nucl Med Mol Imaging. 2007;34:850-858.

25. Philpott GW, Schwarz SW, Anderson CJ, et al. RadioimmunoPET: detection of colorectal carcinoma with positron-emitting copper-64-labeled monoclonal antibody. J Nucl Med. 1995;36:1818-1824.

26. Wu AM, Yazaki PJ, Tsai S, et al. High-resolution microPET imaging of carcinoembryonic antigen-positive xenografts by using a copper-64-labeled engineered antibody fragment. Proc Nat Acad Sci USA. 2000;97:8495-8500.
27. Cai W, Wu Y, Chen K, Cao Q, Tice DA, Chen X. In vitro and in vivo characterization of ${ }^{64} \mathrm{Cu}$-labeled Abegrin, a humanized monoclonal antibody against integrin $\alpha_{\mathrm{v}} \beta_{3}$. Cancer Res. 2006;66:9673-9681.

28. Lovqvist A, Humm JL, Sheikh A, et al. PET imaging of ${ }^{86} \mathrm{Y}$-labeled anti-Lewis $\mathrm{Y}$ monoclonal antibodies in a nude mouse model: comparison between ${ }^{86} \mathrm{Y}$ and ${ }^{111}$ In radiolabels. $J$ Nucl Med. 2001;42:1281-1287.

29. Garmestani K, Milenic DE, Plascjak PS, Brechbiel MW. A new and convenient method for purification of ${ }^{86} \mathrm{Y}$ using a $\operatorname{Sr}(\mathrm{II})$ selective resin and comparison of biodistribution of ${ }^{86} \mathrm{Y}$ and ${ }^{111}$ In labeled Herceptin. Nucl Med Biol. 2002;29:599606.

30. Lovqvist A, Sundin A, Ahlstrom H, Carlsson J, Lundqvist H. Pharmacokinetics and experimental PET imaging of a bromine-76-labeled monoclonal anti-CEA antibody. J Nucl Med. 1997;38:395-401.

31. Rossin R, Berndorff D, Friebe M, Dinkelborg LM, Welch MJ. Small-animal PET of tumor angiogenesis using a ${ }^{76} \mathrm{Br}$-labeled human recombinant antibody fragment to the ED-B domain of fibronectin. J Nucl Med. 2007;48:11721179 .

32. Brouwers A, Verel I, Van Eerd J, et al. PET radioimmunoscintigraphy of renal cell cancer using ${ }^{89} \mathrm{Zr}$-labeled cG250 monoclonal antibody in nude rats. Cancer Biother Radiopharm. 2004;19:155-163.

33. Jayson GC, Zweit J, Jackson A, et al. Molecular imaging and biological evaluation of HuMV833 anti-VEGF antibody: implications for trial design of antiangiogenic antibodies. J Natl Cancer Inst. 2002;94:1484-1493.

34. Divgi CR, Pandit-Taskar N, Jungbluth AA, et al. Preoperative characterisation of clear-cell renal carcinoma using iodine-124-labelled antibody chimeric G250 (124I-cG250) and PET in patients with renal masses: a phase I trial. Lancet Oncol. 2007;8:304-310.

35. Verel I, Visser GW, Boellaard R, et al. Quantitative ${ }^{89} \mathrm{Zr}$ immuno-PET for in vivo scouting of ${ }^{90} \mathrm{Y}$-labeled monoclonal antibodies in xenograft-bearing nude mice. J Nucl Med. 2003;44:1663-1670.

36. Perk LR, Visser GW, Vosjan MJ, et al. ${ }^{89} \mathrm{Zr}$ as a PET surrogate radioisotope for scouting biodistribution of the therapeutic radiometals ${ }^{90} \mathrm{Y}$ and ${ }^{177} \mathrm{Lu}$ in tumorbearing nude mice after coupling to the internalizing antibody cetuximab. $J$ Nucl Med. 2005;46:1898-1906.

37. Perk LR, Visser OJ, Vosjan MJWD, et al. Preparation and evaluation of ${ }^{89} \mathrm{Zr}$ Zevalin for monitoring of ${ }^{90} \mathrm{Y}$-Zevalin biodistribution with positron emission tomography. Eur J Nucl Med Mol Imaging. 2006;33:1337-1345.

38. Borjesson PK, Jauw YW, Boellaard R, et al. Performance of immuno-positron emission tomography with zirconium-89-labeled chimeric monoclonal antibody U36 in the detection of lymph node metastases in head and neck cancer patients. Clin Cancer Res. 2006;12:2133-2140.

39. Johns TG, Perera RM, Vernes SC, et al. The efficacy of epidermal growth factor receptor-specific antibodies against glioma xenografts is influenced by receptor levels, activation status, and heterodimerization. Clin Cancer Res. 2007;13: 1911-1925.

40. Divgi CR, Welt S, Kris M, et al. Phase I and imaging trial of indium 111labeled anti-epidermal growth factor receptor monoclonal antibody 225 in patients with squamous cell lung carcinoma. J Natl Cancer Inst. 1991;83:97104. 